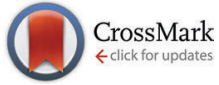

Cite this: Chem. Commun., 2015 51, 1027

Received 31st October 2014, Accepted 23rd November 2014

DOI: $10.1039 / \mathrm{c} 4 \mathrm{cc} 08646 \mathrm{e}$

www.rsc.org/chemcomm

\section{One-step synthesis of patterned polymer brushes by photocatalytic microcontact printing $\dagger$}

\author{
Friederike Kettling, ${ }^{a}$ Benjamin Vonhören, ${ }^{a}$ Jennifer A. Krings, ${ }^{a}$ Susumu Saito ${ }^{b}$ and \\ Bart Jan Ravoo*a
}

\begin{abstract}
A novel method to prepare microstructured polymer brushes using $\mathrm{TiO}_{2}$ nanoparticles and photocatalytic microcontact printing is described. It is shown that ethanol amine can be polymerized to linear polyethyleneimine (PEI) driven by the photocatalytic action of $\mathrm{TiO}_{2}$. Upon UV irradiation during microcontact printing of ethanol amine with a stamp coated with $\mathrm{TiO}_{2}$ nanoparticles, patterned polymer brushes with a length of around $50 \mathrm{~nm}$ are obtained.
\end{abstract}

Microcontact printing ( $\mu \mathrm{CP}$ ) is a well-known method to produce structured surfaces in a simple, rapid and cost efficient way. ${ }^{1-3}$ Although $\mu \mathrm{CP}$ typically relies on chemisorption of ink molecules to a substrate, it has recently been shown that catalysis can also play an important role in surface patterning. An early example of catalytic $\mu \mathrm{CP}$ is the use of the acidic nature of an oxidized polydimethylsiloxane (PDMS) stamp to deprotect acid labile silylether-terminated self-assembled monolayers (SAMs) to produce patterned alcohol surfaces on gold. ${ }^{4}$ Similarly, PDMS stamps can be coated with sulfonic acid functionalized gold nanoparticles (NPs) to pattern an acid labile SAM on gold ${ }^{5}$ or functionalized covalently with sulfonic acids to pattern $N$-hydroxysuccinimide-terminated SAMs on germanium surfaces by deprotection. ${ }^{6}$ In addition it has been shown that enzyme functionalized stamps can be used for biocatalytic $\mu \mathrm{CP} .{ }^{7}$ Furthermore, heterogeneous catalysis with metal coated stamps enabled micropatterned Heck reactions ${ }^{8}$ as well as $\mathrm{Cu}^{\mathrm{I}}$ catalyzed azide-alkyne click chemistry ${ }^{9}$ by $\mu \mathrm{CP}$.

To the best of our knowledge, heterogeneous catalysis combined with $\mu \mathrm{CP}$ has never been used to prepare patterned polymer brushes in one step. Polymer brushes are an important

\footnotetext{
${ }^{a}$ Organic Chemistry Institute, Westfälische Wilhelms-Universität Münster, Corrensstrasse 40, 48149 Münster, Germany. E-mail: b.j.ravoo@uni-muenster.de; Fax: +49 25183 36557; Tel: +4925183 33287

${ }^{b}$ Graduate School of Science and Institute for Advanced Research,

Nagoya University, Chikusa, Nagoya 464-8602, Japan.

E-mail: saito.susumu@f.mbox.nagoya-u.ac.jp; Fax: +81-52-789-5945; Tel: $+81-52-789-5945$

$\dagger$ Electronic supplementary information (ESI) available: Materials, methods and additional experiments and analysis. See DOI: 10.1039/c4cc08646e
}

subject of research since many years ${ }^{10}$ and their remarkable properties on various surfaces leads to a range of applications. Polymer brushes are used to stabilize colloids ${ }^{11}$ and switch the character of a surface from hydrophobic to hydrophilic. ${ }^{12}$ It is possible to control cell adhesion on surfaces treated with polymer brushes. ${ }^{13}$ Polymer brushes can be synthesized using a "grafting to" or a "grafting from" approach. Also the patterning of polymer brushes on surfaces is of great interest for various applications. Typically, the patterned "grafting-from" approach makes use of some lithography method, e.g. micromolding, ${ }^{14}$ photolithography, ${ }^{15}$ electron beam lithography ${ }^{16}$ or $\mu \mathrm{CP}^{17}$ to pattern an initiator onto the surface. Afterwards a surface initiated polymerization is used to build up polymer brushes from solution. The new method presented here requires only a single step for patterning and grafting (Scheme 1). In order to grow polymer brushes of linear polyethyleneimine (PEI) from ethanol amine, the photocatalytic properties of $\mathrm{TiO}_{2} \mathrm{NPs}$ are exploited. Previously, $\mathrm{TiO}_{2}$ was used as photoinitiator for surface initiated $\mathrm{Cu}$-mediated ATRP to prepare polymer brushes and hydrogels. ${ }^{18}$ In spite of the large body of literature on photocatalysis by $\mathrm{TiO}_{2}$ NPs, the photocatalytic step-growth of polymer brushes is unprecedented.

$\mathrm{TiO}_{2}$ NPs were prepared via sol-gel synthesis from $\mathrm{TiCl}_{4}$ and water in diethyleneglycol and have an average diameter of
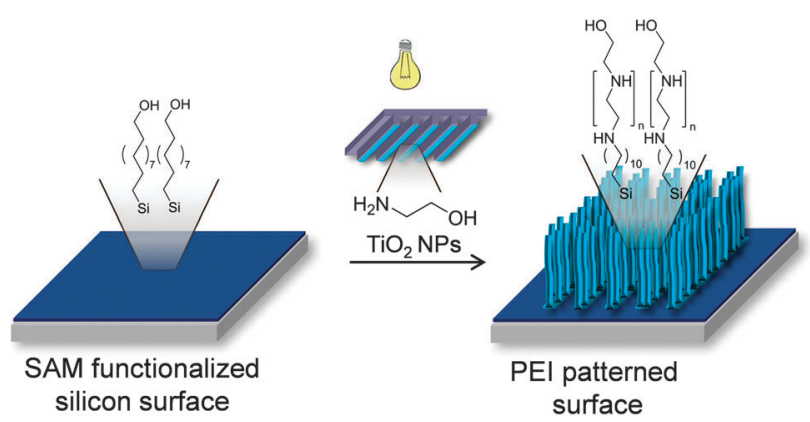

Scheme 1 Photocatalytic polymerization by printing of ethanol amine with $\mathrm{TiO}_{2}$ NPs on a 11-(trichlorosilyl)undecan-1-ol SAM. 


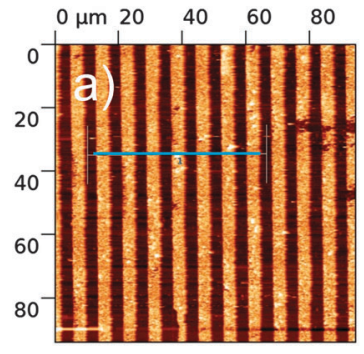

b)

$\begin{array}{llllll}410 & 405 & 400 & 395 & 390 & 385\end{array}$

Binding Energy [eV]

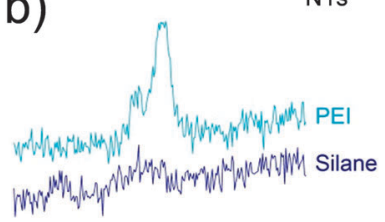

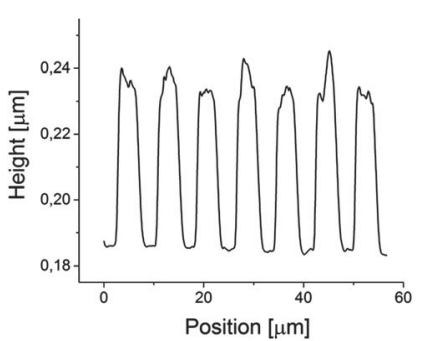

C1s

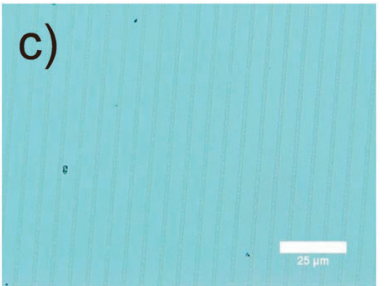

Fig. 1 (a) AFM measurements of patterned PEI brushes (stripes $3 \times 5 \mu \mathrm{m}$ ) with profile height; (b) XPS analysis of PEI brushes compared to bare SAM of 11-(trichlorosilyl)undecan-1-ol; (c) microscopy image of glass slide patterned with PEI brushes (stripes $5 \times 15 \mu \mathrm{m}$ ).

around $5 \mathrm{~nm}$ according to dynamic light scattering (see ESI $\dagger$ ). $\mu \mathrm{CP}$ was performed with a striped PDMS stamp (preparation see ESI $\dagger$ ) which was incubated with $30 \mu \mathrm{L}$ of a methanolic solution of $\mathrm{TiO}_{2}$ NPs and ethanol amine. After $1 \mathrm{~min}$ the stamp was dried in a stream of argon and placed on a silicon (or glass) surface, which was functionalized with a SAM of 11-(trichlorosilyl)undecan-1-ol (for preparation see ESI $\dagger$ ). The transparent stamp and surface were irradiated with UV light for 1 to $45 \mathrm{~min}$. ${ }^{19}$ Afterwards the stamp was removed and the surface was washed and sonicated in dichloromethane, ethanol and milliQ water for $5 \mathrm{~min}$ each to remove physisorbed material, in particular residual $\mathrm{TiO}_{2} \mathrm{NPs}$. AFM measurements (Fig. 1a) show microstructured brushes with an average height of around $58 \mathrm{~nm}$ for an irradiation time of 20 min. As shown in Fig. S1 in the ESI $\dagger$ the length of the polymer brushes tends to increase with the printing time although no strict linear correlation can be observed.

If $\mu \mathrm{CP}$ was performed without $\mathrm{TiO}_{2}$ NPs, no structure was observed on the surface at all. Even optical microscopy images (Fig. 1c) clearly show the formation of a microstructure on the surface. Fig. 1b compares the X-ray photoelectron spectroscopy (XPS) analysis of the surface before (silane SAM) and after (PEI brushes) $\mu \mathrm{CP}$ with a flat PDMS stamp and confirms the immobilization of nitrogen in the polymer. The C1s signal is also present before the printing process due to the alkyl chain of the SAM, but a detailed view reveals a shoulder in the C1s signal of the polymer at around $286 \mathrm{eV}$. This signal is known for

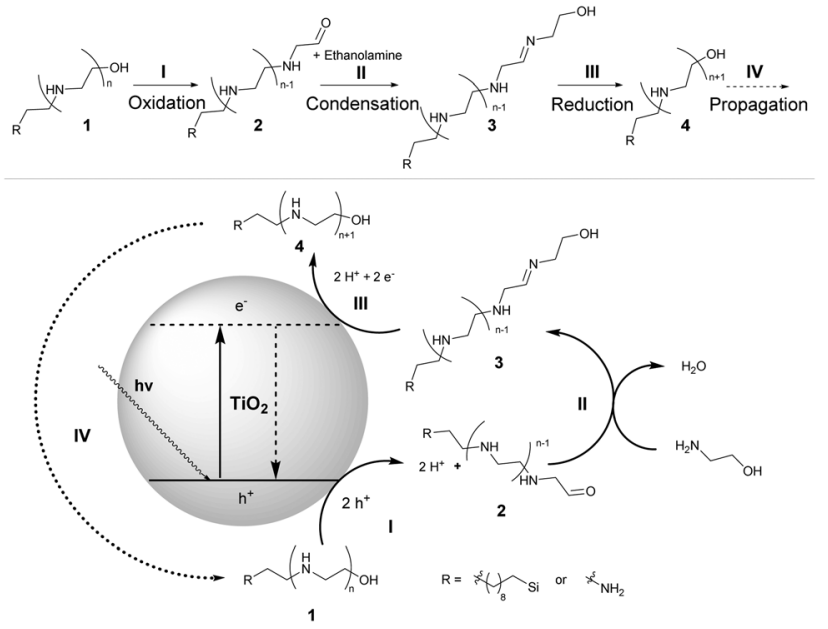

Scheme 2 Proposed reaction mechanism of the photocatalytic stepgrowth polymerization of ethanol amine.

the $\mathrm{C}-\mathrm{N}$ bond of PEI and indicates the presence of PEI on the surface. $^{20}$ The XPS spectrum after printing shows also some remaining $\mathrm{Ti}$ on the surface, which might be due to some $\mathrm{TiO}_{2}$ particles that could not be washed from the surface and were embedded in the polymer brushes. The proposed mechanism of the photocatalytic polymerization can be found in Scheme 2 . We suggest that under UV irradiation the holes $\left(\mathrm{h}^{+}\right)$in $\mathrm{TiO}_{2}$ oxidize compound $\mathbf{1}\left(n=0 ; \mathrm{R}=\mathrm{Si}\left(\mathrm{CH}_{2}\right)_{9}\right)$ as well as ethanol amine to the corresponding aldehyde $\mathbf{2}$ (step I). This aldehyde can react with ethanol amine to imine $\mathbf{3}$ (step II), which can in turn be reduced by the electrons generated from $\mathrm{TiO}_{2}$ to the secondary amine 4 (step III) and finally re-enter the cycle with the unaffected alcohol function as $\mathbf{1}$ (step IV).

To verify whether the immobilized polymer consists of secondary amines or imines, the following experiments were performed. If the imine was not reduced by protons and electrons generated in the $\mathrm{TiO}_{2}$ NPs it should be possible to hydrolyze the polymer under acidic conditions, yet stirring and even boiling in acetic acid at pH 3 (60 mM in water) did not destroy neither the structure nor reduce the height of the brushes on the surface.

Moreover the cationic character of the polymer brushes could be confirmed. To this end, immobilization tests with negatively charged $\mathrm{SiO}_{2}$ nanoparticles (SNPs) with a size of around $60 \mathrm{~nm}$ were performed. ${ }^{21}$ If indeed the polymers are (protonated) amines, not imines, the SNPs will bind strongly to the stripes and can be detected by AFM. In Fig. 2 the AFM measurements of the patterned surfaces before and after incubation with SNPs can be found. Fig. 2a shows the bare polymer brushes before binding at $\mathrm{pH}$ 7. Fig. $2 \mathrm{~d}$ displays the binding behaviour of the SNPs after the standard $\mu \mathrm{CP}$ process at $\mathrm{pH}$ 7. As mentioned above the polymer brushes were washed with water. Because PEI is a weak base, around $15-20 \%{ }^{22}$ of the secondary amine groups will be protonated at $\mathrm{pH}$ 7. This leads to positive charges in the polymer brushes, which attract the negatively charged SNPs. If the polymer brushes are sonicated in $\mathrm{HCl}$ at $\mathrm{pH} 3$ for $15 \mathrm{~min}$, the amount of protonated amines 

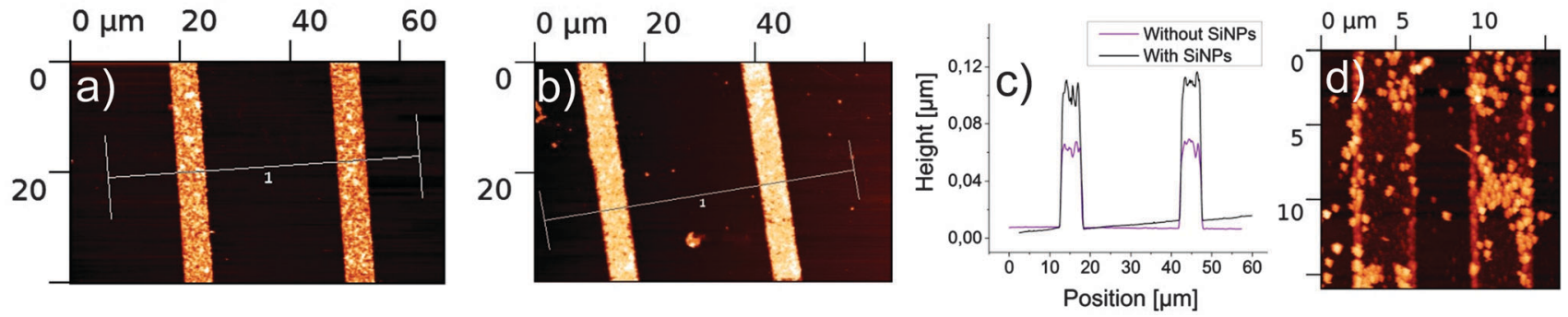

Fig. 2 Immobilization of negatively charged SNPs on protonated PEI brushes; (a) brushes at pH 7; (b) brushes after immobilization of SNPs at pH 3; (c) profile comparison of (a) and (b); (d) brushes after immobilization of SNPs at pH 7.
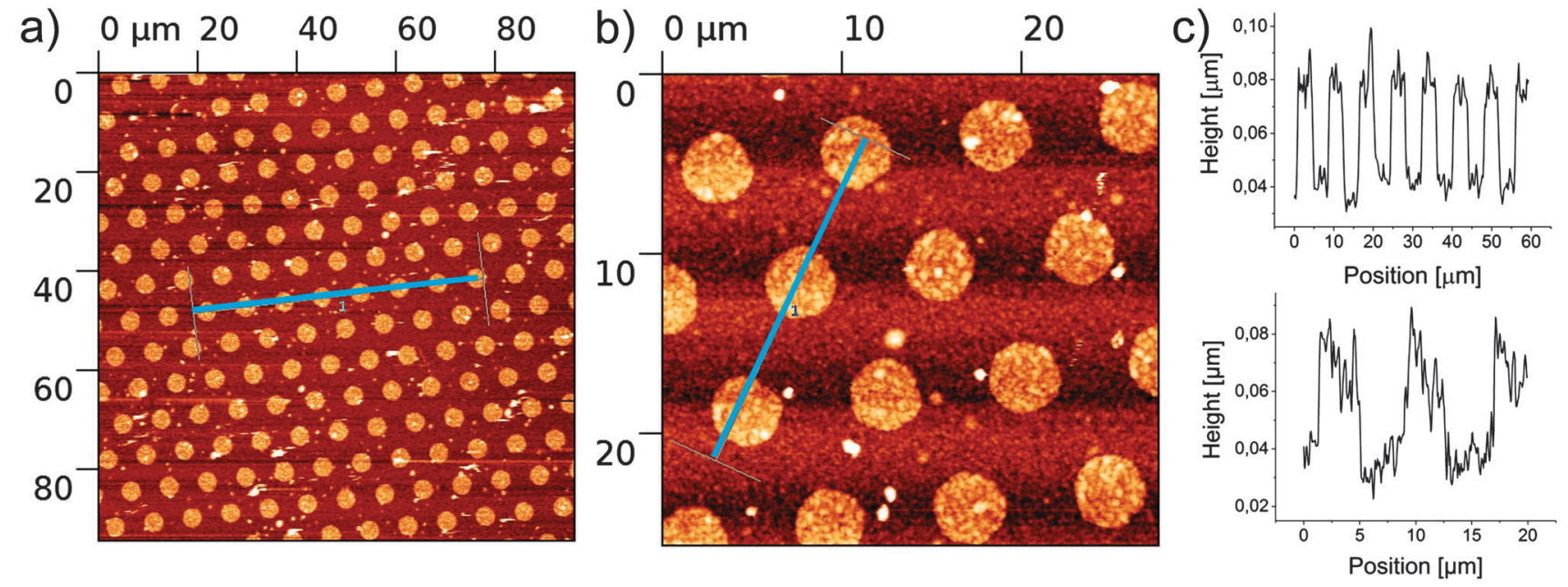

Fig. 3 AFM measurement of ethanol amine polymerized (30 min) onto cellulose; (a) overview; (b) zoom in; (c) profile of blue traces in (a) and (b).

rises to $70-80 \%{ }^{23}$ and, as can be seen in Fig. $2 \mathrm{~b}$, the aggregation of SNPs increases as well. Comparison of the height profiles of Fig. 2a and b clearly demonstrates the attachment of the SNPs (Fig. 2c). The difference between the calculated height (length of polymer plus size of particles) of around $110 \mathrm{~nm}$ and the measured one around $90 \mathrm{~nm}$ might be due to the polymer brushes being slightly compacted upon binding the SNPs.

Finally, to demonstrate that this photocatalytic $\mu \mathrm{CP}$ is a versatile method to modify substrates that display free alcohol functions, the polymerization of ethanol amine was also performed on cellulose surfaces. These were fabricated by spin coating of a solution of cellulose in dimethylacetamide with LiCl on a clean silicon wafer. ${ }^{23,24}$ After washing and drying a layer thickness of around $100 \mathrm{~nm}$ was observed by profilometry (Fig. S2, ESI $\dagger$ ). $\mu \mathrm{CP}$ was performed as described above with a printing time of $30 \mathrm{~min}$, but the cleaning process was reduced to washing with dichloromethane to protect the cellulose coating. In this experiment a dotted stamp $(3 \mu \mathrm{m}$ spots spaced by $5 \mu \mathrm{m}$ ) was used. Fig. 3 displays formation of polymer brushes on the cellulose surface. The profiles in Fig. $3 \mathrm{c}$ indicate that also on cellulose polymers with length of $40 \mathrm{~nm}$ can be achieved. XPS data confirm the successful immobilization (Fig. S3, ESI $\dagger$ ). The N1s signal clearly indicates the immobilization of PEI on cellulose while the $\mathrm{C} 1 \mathrm{~s}$ signal confirms the presence of $\mathrm{C}-\mathrm{N}$ bonds overlaying the $\mathrm{C}-\mathrm{O}$ bond of the cellulose.
In this study the photocatalytic polymerization of ethanol amine by $\mu \mathrm{CP}$ with $\mathrm{TiO}_{2}$ NPs was confirmed by microscopy, AFM and XPS. Using $\mathrm{TiO}_{2}$ NPs it is possible to polymerize ethanol amine on a surface to polyethyleneimine brushes with a length around $50 \mathrm{~nm}$. The use of $\mu \mathrm{CP}$ leads to a well-defined pattern of the polymer brushes. To underline the versatility of this reaction the brushes were printed on SAMs of 11-(trichlorosilyl)undecan-1-ol and also on spin-coated cellulose surfaces, which raises the prospect of micropatterning of PEI on paper. Further investigations regarding the photocatalytic PEI synthesis in solution are ongoing.

We thank the DFG (IRTG 1143 Münster-Nagoya) and the Sustainable Chemical Systems (SusChemSys) program cofinanced by the European Regional Development Fund (ERDF) and the state of North Rhine-Westphalia, Germany, under the Operational Programme "Regional Competitiveness and Employment" (2007-2013) for funding.

\section{Notes and references}

1 Y. Xia and G. M. Whitesides, Angew. Chem., Int. Ed., 1998, 37, 550-575.

2 C. Wendeln and B. J. Ravoo, Langmuir, 2012, 28, 5527-5538.

3 A. Perl, D. N. Reinhoudt and J. Huskens, Adv. Mater., 2009, 21, 2257-2268.

4 X.-M. Li, M. Péter, J. Huskens and D. N. Reinhoudt, Nano Lett., 2003, 3, 1449-1453.

5 X.-M. Li, V. Paraschiv, J. Huskens and D. N. Reinhoudt, J. Am. Chem. Soc., 2003, 125, 4279-4284. 
6 C. J. Morris, A. A. Shestopalov, B. H. Gold, R. L. Clark and E. J. Toone, Langmuir, 2011, 27, 6486-6489.

7 P. W. Snyder, M. S. Johannes, B. N. Vogen, R. L. Clark and E. J. Toone, J. Org. Chem., 2007, 72, 7459-7461.

8 H. Mizuno and J. M. Buriak, ACS Appl. Mater. Interfaces, 2010, 2, 2301-2307.

9 J. M. Spruell, B. A. Sheriff, D. I. Rozkiewicz, W. R. Dichtel, R. D. Rohde, D. N. Reinhoudt, J. F. Stoddart and J. R. Heath, Angew. Chem., Int. Ed., 2008, 47, 9927-9932.

10 S. T. Milner, Science, 1991, 251, 905-914.

11 D. Maillard, S. K. Kumar, A. Rungta, B. C. Benicewicz and R. E. Prud'homme, Nano Lett., 2011, 11, 4569-4573.

12 A. Sidorenko, S. Minko, K. Schenk-Meuser, H. Duschner and M. Stamm, Langmuir, 1999, 15, 8349-8355.

13 (a) O. Hyeong Kwon, A. Kikuchi, M. Yamato and T. Okano, Biomaterials, 2003, 24, 1223-1232; (b) C. Rodriguez-Emmenegger, C. M. Preuss, B. Yameen, O. Pop-Georgievski, M. Bachmann, J. O. Mueller, M. Bruns, A. S. Goldmann, M. Bastmeyer and C. Barner-Kowollik, Adv. Mater., 2013, 25, 6123-6127.

14 C. A. Escobar, T. J. Cooksey, M. P. Spellings and G. K. Jennings, Adv. Mater. Interfaces, 2014, DOI: 10.1002/admi.201400055.

15 O. Prucker, M. Schimmel, G. Tovar, W. Knoll and J. Rühe, Adv. Mater., 1998, 10, 1073-1077.
16 S. J. Ahn, M. Kaholek, W.-K. Lee, B. LaMattina, T. H. LaBean and S. Zauscher, Adv. Mater., 2004, 16, 2141-2145.

17 (a) P. Xiao, J. Gu, J. Chen, D. Han, J. Zhang, H. Cao, R. Xing, Y. Han, W. Wang and T. Chen, Chem. Commun., 2013, 49, 11167-11169; (b) O. Roling, A. Mardyukov, S. Lamping, B. Vonhören, S. Rinnen, H. F. Arlinghaus, A. Studer and B. J. Ravoo, Org. Biomol. Chem., 2014, 12, 7828-7835.

18 (a) B. Li, B. Yu and F. Zhou, Macromol. Rapid Commun., 2014, 35, 1287-1292; (b) J. Yan, B. Li, F. Zhou and W. Liu, ACS Macro Lett., 2013, 2, 592-596; (c) D. Zhang, J. Yang, S. Bao, Q. Wu and Q. Wang, Sci. Rep., 2013, 3, 1399.

19 C. Wendeln, S. Rinnen, C. Schulz, H. F. Arlinghaus and B. J. Ravoo, Langmuir, 2010, 26, 15966-15971.

20 E. P. Dillon, C. A. Crouse and A. R. Barron, ACS Nano, 2008, 2, 156-164.

21 L. M. Rossi, L. Shi, F. H. Quina and Z. Rosenzweig, Langmuir, 2005, 21, 4277-4280.

22 J. Suh, H. J. Paik and B. K. Hwang, Bioorg. Chem., 1994, 22, 318-327.

23 K. Han, K.-S. Kang and J. Kim, J. Micromech. Microeng., 2009, 19, 035010.

24 K. Rahn, M. Diamantoglou, D. Klemm, H. Berghmans and T. Heinze, Angew. Makromol. Chem., 1996, 238, 143-163. 